\title{
Dispersion of Multi-Walled Carbon Nanotubes Using Polyvinylpyrrolidone for Application in Cement - Based Composites to Enhance Electrical Conductivity
}

\author{
Ghimire Prateek $1,3,4, *$, Yulin Wang ${ }^{1,2,3, *}$, Henggan Li ${ }^{1,2}$, Yuanfu Ban ${ }^{1}$, Hao Luo', Danping Lin', \\ Jinglong Yang ${ }^{\top}$, Shuyan Lin ${ }^{\top}$, Zhengyang Pan ${ }^{\top}$, Qingwei Su' \\ ${ }^{1}$ Department of Civil Engineering and Architecture, Wuyi University, Wuyishan City, 354300, China \\ ${ }^{2}$ Provincial Engineering Research Centre of Prevention and Control of Geological Hazards of Mountainous Region of \\ Northern Fujian Province, Wuyishan City, 354300, China \\ ${ }^{3}$ Fujian Higher Education Institution's Key Laboratory of Smart Town Construction of Hilly Mountains, Wuyishan City, \\ 354300, China \\ ${ }^{4}$ Overseas Education College, Wuyi University, Wuyishan City, 354300, China
}

*Corresponding author: E-mail: meinchinananjing@gmail.com, ylwanghm@163.com; Tel: (+86) 18350929289, (+86) 13960678993

DOI: $10.5185 / \mathrm{amlett} .2020 .061525$

The purpose of this study is to analyse the effective method of dispersion of MWCNTs for the application in cement-based composites. Efficient dispersion of Carbon Nanotubes (CNTs) is one of the most challenging and crucial aspects for the application in cement-based composite. In this study, two different CNTs, pristine and functionalized (p-MWCNTs and f-MWCNTs) were dispersed in deionized water using different surfactants, Polyvinylpyrrolidone (PVP k-30 and PVP k-90) \& Sodium Dodecyl Sulfate (SDS) and conducted a comparative investigation of the effects. Dispersion using an ultrasonic, treatment with surfactant and integrated method of both were analysed. The influence of CNTs dispersion on the electrical conductivity of the aqueous solution and to cement composites has been studied. Among the surfactant used PVPk-30 provide the best-dispersing effect while PVPk$30+$ SDS shows an extraordinary enhancement of conductivity of an aqueous solution. Analysis of electrical conductivity of Various \% CNTs' loaded specimen $(0,0.001,0.003,0.025$ wt.\%) with different curing period $(3,7,14,21,28$ days) showed that the electrical resistivity decreases with CNTs' loading. Dispersion effect of surfactant on p-MWCNTs and f-MWCNTs has been characterized by Ultravioletvisible Spectroscopy (UV-Vis) and electrical resistivity measurement is carried for investigation and comparison on enhancement of electrical conductivity.

\section{Introduction}

Beginning with the first evidence of the tubular hollow graphitic nature of nano-sized carbon filaments of $50 \mathrm{~nm}$ in diameter by Monthioux and Kuznetsov [1], which dates back as far as 1952. Their further rediscoveries, including the high impact report on the synthesis of hollow carbon molecules \& their crystal structures by arc discharge evaporation method for the first time by Japanese researcher Sumio Iijima published in 1991 [2], the field of CNTs continues to be one of the hottest topics in nanoscience and nanotechnology which has been already around 30 years. Nano carbons are the carbon allotropes with nanometer-scale composed mainly of (0D-3D) dimensional forms; fullerenes(0D), found by Kroto and Smelly in 1985 [3], carbon nanotubes, (1D), graphene (2D), found by Novoselov and Geim in 2004 [4] and nano diamond (3D), found by Soviet scientists in July 1963. CNTs are a hexagonal array of carbon atoms rolled up into a long thin, hollow cylinder and are known for their size, shape, and remarkable properties. CNT has a diameter of the order of few nm while its length can be of the order of few $\mu \mathrm{m}$ (in some cases up to several $\mathrm{cm}$ ). The length to diameter ratio (aspect ratio) can be exceeded up to 132000000:1. CNTs can be classified to many types such as Single-walled, double-walled, multiwalled, polymerized CNT, nano torus, Nanobuds (CNT+ Fullerenes), etc. CNTs are defined as rolled up from a single planar sheet of graphene in case of Single-Walled Carbon Nanotubes (SWCNTs) and multiplanar sheets in case of MWCNTs. Two models can be used to describe the structure of MWCNTs, Russian model explains as sheets of graphite which are arranged in concentric cylinders within larger single SWCNTs while the parchment model describes as a single sheet of graphite rolled in around itself, resembling a scroll of parchment or rolled paper.

Researcher's great interests have been attracted by CNTs by its tiny size structure and exhibiting many interesting and often unexpected and extraordinary mechanical [5-7] electric [8], thermal stability [9] and 


\section{Advanced Materials Letters www. vbripress.com/aml}

optical [4] properties because of which a great application in electro chemical, biosensors and chemical sensors [10], composites [11], field emission devices [12], gas or energy storage, probe tips, etc. It is predicted that introducing CNTs into cement-based materials via nanotechnology will open up a whole wide range of multifunctional cement-based materials. As far as the mechanical behavior, CNTs are highly resilient. Nanotubes are the stiffest known fiber, with a measured Young's modulus of 1.4 TPa and elongation to failure of 20-30\%, which projects to a tensile strength of well above $100 \mathrm{GPa}$ (possibly higher) by far the highest known. For comparison, Young's modulus of high-strength steel is around $200 \mathrm{GPa}$, and its tensile strength is $1-2 \mathrm{GPa}$. CNT has been shown to have a thermal conductivity at least twice that of diamond and they have five times the Young's modulus and eight times (theoretically 100 times) the strength of steel, whilst being 1/6th the density. CNTs are a spectacular invention in the history of material science that has enhanced the properties of the composite material to a new level. However, some drawbacks have been found, as they tend to cluster in bundles thus making the interaction with the cement matrix inefficient and the bond between CNTs and matrix is weak. Nanotechnology applied in the cement matrix is still in an intense phase of research. Also, some research works have been carried out for different techniques to improve fatigue behavior [1315] and interface strengthening [16] of various sorts of fiber reinforced epoxy composites. Through the recent research of different scholars, it is found a remarkable properties enhancement of cement matrix with CNTs inclusion like enhanced compressive strength and pore filling [5], increase in flexural strength [17], strain sensing, thermal sensing, electromagnetic inference shielding, electrical heating, cathodic protection for steel elements. Because of CNTs huge specific surface area which is around $\left(50-1315 \mathrm{~m}^{2} \mathrm{~g}^{-1}\right)$, Strong van der Waal's force between tubes which makes a bundle like entanglement and aggregates, large aspect ratio up to 1 million times the length, which largely exceeds that of other known material and extreme high cohesive force (e.g. SWCNTs with length $100 \mathrm{~nm}$ could reach up to $2.9 \mathrm{keV}$ ) these factors makes the urgency of dispersion of nanoparticles before using in composite materials. Hence proper dispersion and adequate load transfer is the most challenging aspect in the various research field [11].

Here in this study we mainly focus on the dispersion of CNTs for the application in cement-based materials to reduce the electrical resistance. The very basic question when dealing with CNTs in liquids, (particularly in water) is: are CNTs dissolved or dispersed? Hence is suggested using the term "dispersion" rather than "solution". Lack of standards and uniform characterization methods for CNTs dispersion is also one of the most problematic issues in the research sector. The history of functionalization and solubilization of CNTs is not so long. Broadly the dispersion techniques of CNTs for the application in various fields can be grouped in three methods, physical, chemical and biological. Contemporary physical methods include ultrasonication, plasma treatment, hydrothermal method, UV and visible light techniques, microwave treatment, pulsed streamer discharge, irradiation techniques and labeling, electric field induction and so on. Chemical methods like functionalization leading to soluble CNTs treating with inorganic compounds (ozone, inorganic peroxides liquid ammonia, elemental metals and non-metals, inorganic salts and oxides, inorganic acids and their mixtures), organic compounds like aliphatic, aromatic, and polyaromatic compounds, organic acids their salts, and other compounds containing O-containing moieties, N- containing moieties, S-containing moieties, organic dispersants (Rhodamine B and fluorescein), polymers and their precursors. Biological method of CNT dispersion treating with sugar and their derivatives and biomolecules is also quite popular. Single dispersion method can hardly achieve the optimal dispersing effect on CNTs therefore an integrated method which is a combining of several methods can magnify the dispersing effect, which also helps in increasing the efficiency of dispersion as well as shortens the dispersing time. In our following experimental study, we use the integrated dispersion method (ultrasonication and using surfactant) to achieve a good and stable dispersion of CNTs. Table 1 depicts a brief comparison on various popular techniques, their based principle, advantages and disadvantages used to achieve stable and good dispersion of CNTs for the application on cement-based composites to enhance various properties.

During the ultrasonic action on aqueous MWCNTs, a classic De-bundling method can be considered where cavitation process produces the high shear stresses which can de-bundle CNT clusters easily, leading to exfoliation of CNTs, bubble formation, and collapses, finally providing homogeneity of nanosuspension. Ultrasonic method alone is hard to achieve the optimal dispersing effect because incoming ultrasonic waves in liquid are usually reflected and damped at the gas/liquid interface, it also has poorest post-dispersion stability and the ultrasonication induced dispersion is found to be reversible in short term. In covalent chemical method, where CNTs are treated with aggressive chemicals like $\mathrm{HNO}_{3} / \mathrm{H}_{2} \mathrm{SO}_{4}$, ozone, etc. which creates defects on the surface of CNTs, consequently alteration in CNTs properties. Hence a non-covalent chemical method is considered to be better as it has less influence on the $\pi$ electron cloud of CNTs. It also preserves the excellent properties of attaching a variety of chemical groups on the CNTs surface. Surface modification by surfactants and integrated with ultrasonication method is the most popular techniques at the present and is considered to be the most reasonable method for dispersion because this method led to minimal damage on the original CNTs which is accompanied with a low cost and higher controllability.

SDS is one of the most commonly used water soluble amphiphilic dispersants, which helps to de-bundle CNT by electrostatic and steric repulsion [18]. PVP is polymeric 


\section{Advanced Materials Letters www. vbripress.com/aml}

surfactants [19], has a good stable to environment, easy processing and moderate electric conductivity [4]. Which tends to wrap around the CNTs center through their flexible or semi-flexible sections with dispersion mechanism of stacking/Amine e-pair donation. For the first time by O'Connell et al. using Atomic Force Microscopy images showed that any aqueous of polymer (Polyvinylpyrrolidone) would be wrapping the surface of the nanotubes [11]. Also in 2002, O'Connell et al. presented the evidence of the SDS-PVP system showing peaks that were red-shifted and broadened compared to SDS dispersed system [20].

Table 1. A brief comparison on various popular techniques, their based principle, advantages and disadvantages used to achieve stable and good dispersion of CNTs for the application on cement-based composites.

\begin{tabular}{|c|c|c|c|}
\hline $\begin{array}{l}\text { Dispersion } \\
\text { method }\end{array}$ & Principle & Advantages & Disadvantages \\
\hline $\begin{array}{l}\text { Mechanical } \\
\text { dispersion }\end{array}$ & $\begin{array}{l}\text { causes dispersion } \\
\text { using the shear } \\
\text { force. }\end{array}$ & $\begin{array}{l}\text { less apparatus, } \\
\text { simple operation }\end{array}$ & $\begin{array}{l}\text { brings to } \\
\text { macroscopic } \\
\text { dispersion, } \\
\text { damage particle, } \\
\text { poor effect }\end{array}$ \\
\hline $\begin{array}{l}\text { Ultrasonic } \\
\text { dispersion }\end{array}$ & \begin{tabular}{l|} 
causes dispersion \\
using the impact \\
and high \\
temperature \\
created by \\
ultrasonic wave.
\end{tabular} & $\begin{array}{l}\text { breaks the } \\
\text { internal } \\
\text { dangling bonds, } \\
\text { resulting in } \\
\text { multifunctional } \\
\text { effect. }\end{array}$ & $\begin{array}{l}\text { needs special } \\
\text { ultrasonic } \\
\text { apparatus, breaks } \\
\text { particle, reduces } \\
\text { its length }\end{array}$ \\
\hline $\begin{array}{l}\text { Electric field } \\
\text { induction }\end{array}$ & $\begin{array}{l}\text { use electric field } \\
\text { force to disperse }\end{array}$ & $\begin{array}{l}\text { disperse along } \\
\text { the direction of } \\
\text { electric field, } \\
\text { composites with } \\
\text { good electrical } \\
\text { conductivity is } \\
\text { produced }\end{array}$ & $\begin{array}{l}\text { complex } \\
\text { apparatus and } \\
\text { devices, the } \\
\text { dispersed state } \\
\text { cannot be } \\
\text { maintained after } \\
\text { the removal of } \\
\text { electric field }\end{array}$ \\
\hline $\begin{array}{l}\text { Electric field } \\
\text { induction }\end{array}$ & \begin{tabular}{|l|} 
introduces \\
modification \\
functional groups \\
to enhance the \\
reactivity and \\
wettability
\end{tabular} & $\begin{array}{l}\text { eliminates } \\
\text { impurities, } \\
\text { creates good } \\
\text { bonding force } \\
\text { between particle } \\
\text { and hydration } \\
\text { products of } \\
\text { cement-based } \\
\text { composites }\end{array}$ & $\begin{array}{l}\text { using corrosive } \\
\text { chemicals is } \\
\text { needed, which } \\
\text { could bring } \\
\text { damage to particle }\end{array}$ \\
\hline $\begin{array}{l}\text { Non-covalent } \\
\text { chemical } \\
\text { modification }\end{array}$ & $\begin{array}{l}\text { makes use of } \\
\text { hydrophilicity } \\
\text { of surfactant to } \\
\text { reduce the Van } \\
\text { der force between } \\
\text { particles }\end{array}$ & $\begin{array}{l}\text { best dispersing } \\
\text { effect, doesn't } \\
\text { damage the } \\
\text { structure and } \\
\text { mechanical } \\
\text { properties of } \\
\text { particles }\end{array}$ & $\begin{array}{l}\text { incompatibility } \\
\text { between } \\
\text { surfactants and } \\
\text { cement matrix } \\
\text { which affects the } \\
\text { hydration reaction }\end{array}$ \\
\hline $\begin{array}{l}\text { Integrated } \\
\text { dispersion } \\
\text { method }\end{array}$ & $\begin{array}{l}\text { Integrates the } \\
\text { application of } \\
\text { aforementioned. }\end{array}$ & $\begin{array}{l}\text { more obvious } \\
\text { dispersing } \\
\text { effect, higher } \\
\text { dispersing } \\
\text { efficiency, } \\
\text { shorter } \\
\text { dispersing time. }\end{array}$ & $\begin{array}{l}\text { requires } \\
\text { combination of } \\
\text { various methods } \\
\text { to effectively } \\
\text { cooperate. }\end{array}$ \\
\hline
\end{tabular}

In this study Integrated dispersion method (where the application of surfactant as well as treatment of ultrasonication method is applied simultaneously). The comparative dispersion efficiency of two different types of CNTs and good and stable dispersion ability of all three surfactants are analyzed. Different $\%$ composition of
CNTs, different ratio of CNTs to surfactants, variable ultrasonic time was also studied along with UV-vis spectroscopy, electrical resistivity measurement of on aqueous sample and on cement composite specimen.

\section{Materials and methods}

\section{Materials}

Pristine MWCNTs and functionalized MWCNTs (MWCNTs with $-\mathrm{COOH}$ functional group, Carboxylate) were purchased from www.aladdin-e.com (an online chemicals and lab equipment purchasing platform in China). It claims that nanoparticles were characterized as qualitatively and quantitatively by $\mathrm{X}$-ray photoelectron spectroscopy (XPS) and Boehm titration. The main physical properties of p-MWCNTs and f-MWCNTs are briefly depicted in below Table 2. PVP k-30, PVP k-90, and SDS were used as surfactants to disperse p-MWCNTs and f-MWCNTs in de-ionized water. The cement used for specimen preparation is ordinary Portland $42.5 \mathrm{R}$ cement. The all above-mentioned materials were used without any further purification.

Table 2. Main physical properties of p-MWCNTs and f-MWCNTs.

\begin{tabular}{l|c|c|c|c|c|c}
\hline Type & $\begin{array}{c}\text { OD } \\
(\mathbf{n m})\end{array}$ & $\begin{array}{c}\text { ID } \\
(\mathbf{n m})\end{array}$ & Purity & length & Ash & $\begin{array}{c}\text { SSA } \\
\left(\mathbf{m}^{2} \mathbf{g}^{-1}\right)\end{array}$ \\
\hline p-MWCNTs & $8-15$ & $3-5$ & $>95 \%$ & $\sim 50 \mu \mathrm{m}$ & $<6 \%$ & $250 \sim 300$ \\
\hline f-MWCNTs & $30-50$ & $5-12$ & $>90 \%$ & $10-20 \mathrm{~nm}$ & $<6 \%$ & $>40$ \\
\hline
\end{tabular}

Note: OD: outer diameter, ID: Inner diameter, SSA Specific surface Area.

Preparation of MWCNTs dispersion with various surfactants to compare the dispersing ability of the different surfactants (PVP k-30, PVP k-90, and SDS) and to establish the optimal CNTs/Surfactants ratio, various aqueous sample of CNTs with surfactants in water were prepared from $0.015 \mathrm{Wt} . \%$ to $1.0 \mathrm{Wt}$.\% of CNT's loading. Different concentration of p-MWCNTs and f-MWCNTs were prepared in $100 \mathrm{ml}$ of de-ionized water into a beaker. Single and combined treatment of CNTs with different surfactants in various concentration of surfactant and CNT's loading is also carried out. Carefully, all the beakers for the experiment were cleaned and dried in Glass Instrument Air Dryer before using for each set of experiment. Materials used were weighted and carefully poured in $100 \mathrm{ml}$ de-ionized water in a beaker. Firstly, surfactants were mixed in water and stirred using a glass rod for $90 \mathrm{~s}$ and weighted carbon nanotubes are mixed and again stirred for $60 \mathrm{~s}$. A brief illustration of the experimental program is as shown in Fig. 1. The dissolution was performed with ultrasonication treatment in ultrasonic cell crusher set to different amplitude ranging from $25 \%$ to $100 \%$ and the result of electrical conductivity, capacitance is compared and analyzed. Ultrasonic device (maximum input Electric Power $900 \mathrm{~W}$, output $360 \mathrm{~W}$, working frequency $40 \mathrm{KHZ} \pm 2 \mathrm{KHz}$ ) is purchased from Zealway Instrument company Xiamen China. Visual observation is also carried out for different CNT's loading. After the completion of different ultrasonication duration, the aqueous sample was diluted 


\section{Advanced Materials Letters www. vbripress.com/aml}

10 times and measured by visual observation and UV-Vis spectrometer. UV-Vis spectrometry is carried out by using V-1200 Spectrophotometer (Photometric range: -0.3 to 3.0 Abs., 0-200\% Trans., AC 220/110, 50-60 Hz, wavelength range: $325-1000 \mathrm{~nm}$, Spectral bandwidth: 4nm, stray light: $\leq 0.3 \% \mathrm{~T} @ 340 \mathrm{~nm}$ ) purchased from Shanghai Mapada Instrument Company. Each sample for UV-Vis spectrometry analysis was measured three times with wavelength ranging from $325 \mathrm{~nm}$ to $1000 \mathrm{~nm}$ and an average absorbance value is recorded. Electrical resistance and Capacitance of aqueous solution is measured using UC 2876 high-frequency precision LCR Meter.

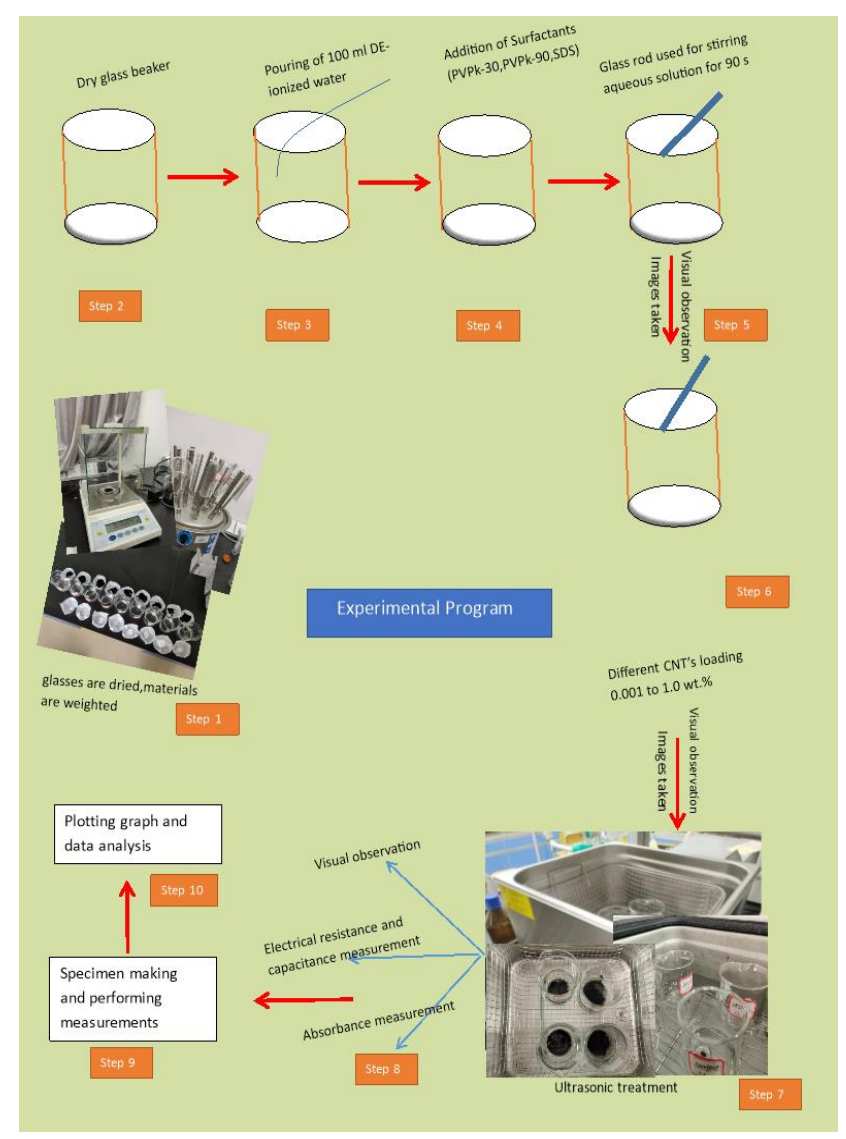

Fig. 1. Brief illustration of experimental program.

\section{Characterization of MWCNTs dispersion}

A Suspension containing different CNT's loading and various CNTs/Surfactants ratio after various duration of ultrasonication were used for analysis. During each set of an experiment before the beginning of ultrasonication and the completion of each ultrasonication duration $(30,60,90$ mins) the samples were measured for recording electrical resistance and capacitance. Next, a pipette tip was carefully used to suck up $1.0 \mathrm{ml}$ of the suspension and dipped it in a glass beaker containing $10 \mathrm{ml}$ of deionized water. Careful visual observation of the morphology of the aqueous sample was done with the naked eye. After the macroscopic observation, the dispersion quality and state of the suspension were measured by UV-Vis spectroscopy with different concentration, CNTs/ surfactants ratio, sonication time with wavelength ranging from $325 \mathrm{~nm}$ to $1000 \mathrm{~nm}$ and obtained average absorbance values were recorded for further analysis.

\section{Specimen preparation}

Altogether four sets of specimens were prepared with mixing proportion as illustrated in Table 3. For each set there were three specimens.

Table 3. Mixing proportion of all specimens.

\begin{tabular}{|c|c|c|c|c|c|c|}
\hline S.N. & $\begin{array}{c}\text { Specimen } \\
\text { name }\end{array}$ & $\begin{array}{c}\text { CNT's } \\
\text { loading }\end{array}$ & $\begin{array}{c}\text { Cement } \\
\text { (g) }\end{array}$ & $\begin{array}{c}\text { Water } \\
(\mathrm{g})\end{array}$ & $\begin{array}{c}\text { CNTs } \\
\text { (g) }\end{array}$ & $\begin{array}{c}\text { Water } \\
\text { cement } \\
\text { ratio }\end{array}$ \\
\hline 1 & PBN & $0.00 \mathrm{w}$ & \multirow{4}{*}{1382.40} & \multirow{4}{*}{580.61} & 0.00 & \multirow{4}{*}{0.42} \\
\hline 2 & PBM001 & 0.001 wt.\% & & & 0.138 & \\
\hline 3 & PBM003 & $0.003 \mathrm{wt} \%$ & & & 0.414 & \\
\hline 4 & Pbm025 & 0.025 wt.\% & & & 3.456 & \\
\hline
\end{tabular}

Note: The ratios in above table are per weight.

\section{Specimen preparation process}

First of all, the needed raw materials were weighted according to the designed mixing proportions as depicted in Table 2. Afterwards, around half of the cement was poured into stirring pot along with the water and CNT solution (the CNT used here are applied integrated dispersion approach as mentioned above with $120 \mathrm{~m}$ ultrasonic time, with PVP k-30 as surfactant) for a slow 60 $\mathrm{s}$ stir which is followed by rapid $30 \mathrm{~s}$ stir, then the remaining half of cement was poured in the same procedure. Finally, a $60 \mathrm{~s}$ slow and $30 \mathrm{~s}$ fast stir was carried out. The well-stirred mixtures were put into oiled molds and those molds were put onto a vibrating table and shaken until oozing slurry was observed on the surface of the specimens. The dimension of the specimens was $40 \mathrm{~mm} \times 40 \mathrm{~mm} \times 160 \mathrm{~mm}$. Two copper electrodes were embedded in the corresponding position (at $10 \mathrm{~mm}$ from left/right and $10 \mathrm{~mm}$ from the end) of the specimen. All specimens were de-molded after 24 hours and were put in a standard curing box $20 \pm 10$ c and relative humidity $(\mathrm{RH}) \geq 90 \%$ ). They were cured in water at $20 \pm 10$ c for 28 days. On $3^{\text {rd }}, 7^{\text {th }}, 14^{\text {th }}, 21^{\text {st }}$ and $28^{\text {th }}$ day the electrical resistance is measured. The obtained data is used for further investigation.

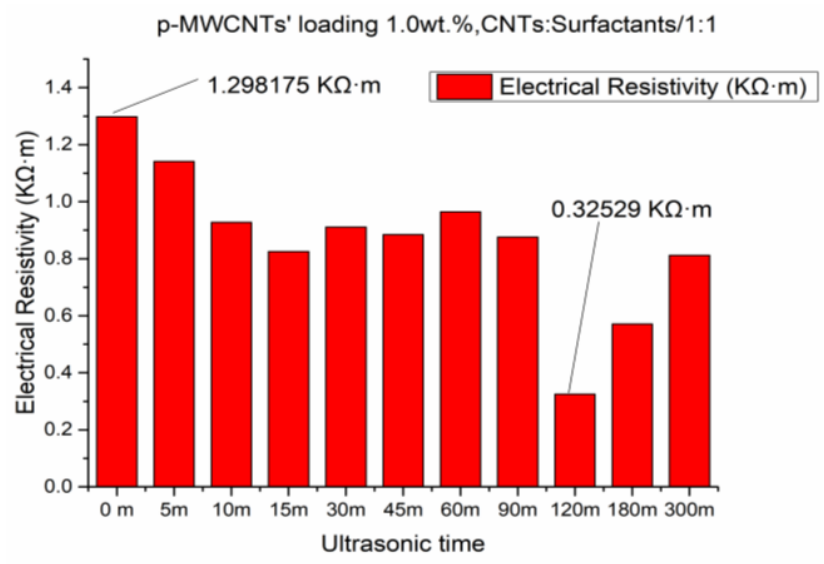

Fig 2. Relation between electrical resistivity and ultrasonic time for 1.0 wt. \% p-MWCNTs loading with CNTs: PVP k-30/1:1. 


\section{Advanced Materials Letters www. vbripress.com/aml}

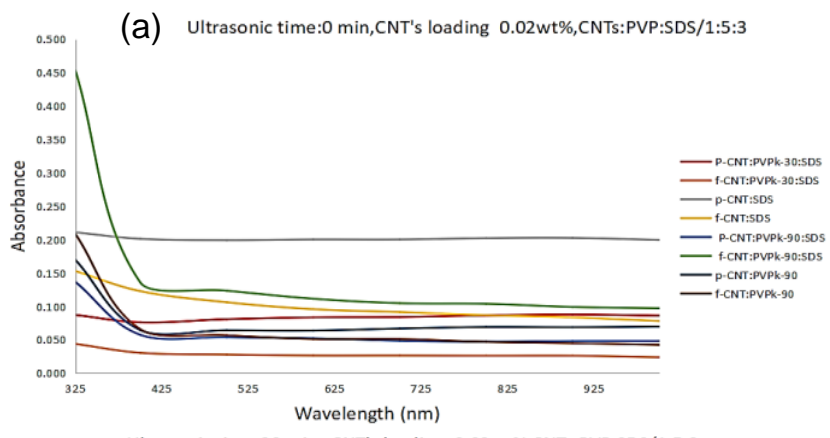

Ultrasonic time:30 mins,CNT's loading $0.02 w t \%, C N T s: P V P: S D S / 1: 5: 3$

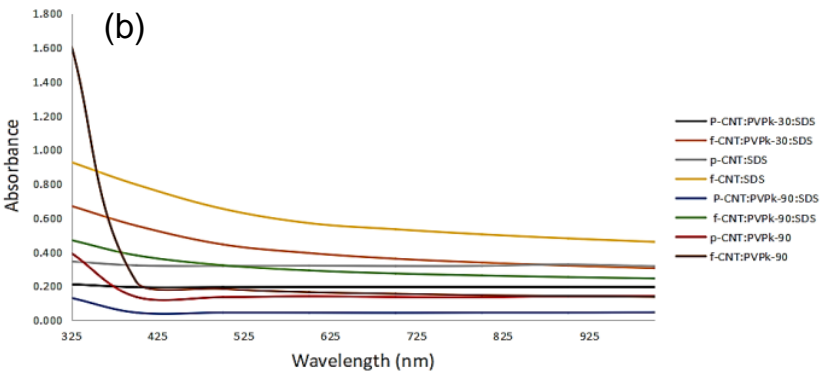

Ultrasonic time:60 mins,CNT's loading $0.02 \mathrm{wt} \%, \mathrm{CNTs}: \mathrm{PVP}: \mathrm{SDS} / 1: 5: 3$

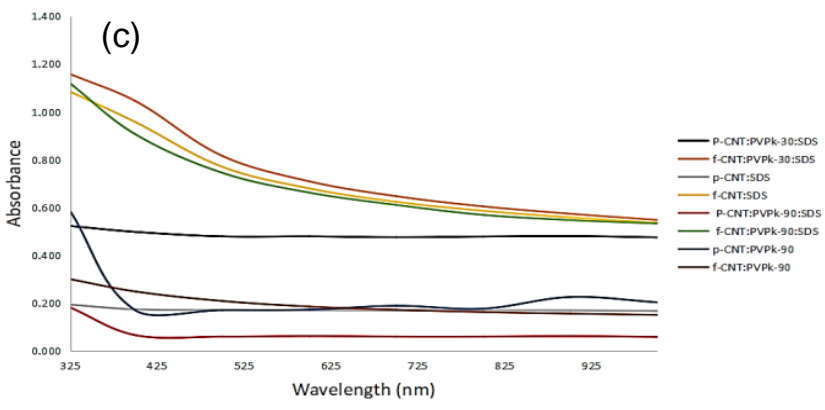

Ultrasonic time:90 mins, CNT's loading $0.02 w t \%, C N T s: P V P: S D S / 1: 5: 3$

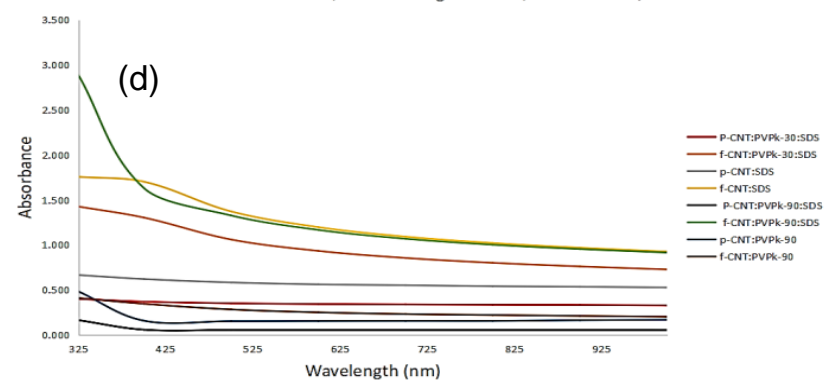

Fig. 3. Relation between absorbance vs wavelength, CNTs' loading 0.02 wt.\%, CNTs:PVPk-30:SDS/1:5:3 (a) ultrasonic time 0 min, (b) ultrasonic time $30 \mathrm{~min}$, (c) ultrasonic time $60 \mathrm{~min}$, (d) ultrasonic time $90 \mathrm{~min}$.

\section{Result and discussion}

When $1.0 \mathrm{wt} \%$ of p-MWCNT's loading for eleven samples, each were prepared and carried ultrasonic treatment from 0 min to $300 \mathrm{~min}$ with the application of PVP k-30 as surfactant with CNTs/surfactant ratio 1:1, we observed $120 \mathrm{~min}$ found to be having a lowest electrical resistivity as seen in Fig. 2. It depicts an enhancement of electrical conductivity of aqueous sample more than four times in comparison to electrical conductivity at $0 \mathrm{~min}$. It is believed that cavitation process produces the high shear stresses which de-bundled CNT clusters. It leaded to exfoliation of CNT and finally provided homogeneity of nanosuspension on comparison to non-sonicated sample. When two different MWCNTs (pristine and functionalized) combined with two different molecular weight PVP (PVP k-30 and PVP k-90) separately at CNTs/Surfactant ratio of 1:5 for CNTs/PVP and 1:3 for CNTs/SDS, and performed ultrasonic treatment for a various duration ranging from $0-90 \mathrm{~min}$. The UV-Vis spectroscopy study for each sample and analysis of the Absorbance vs Wavelength graph showed that the efficiency of PVPk-90 is less than PVP k-30 for good dispersion and enhancement of conductivity. It is because PVP k-90 having a higher molecular weight a long polymer chain could have wrapped more than a single MWCNTs together or single nanotube wrapped entirely, which leaded to higher surface coverage then compromising the formation of a conductive route. This could have hindered the transport of electrons on overall suspension [21]. Molecular weight of applied surfactants for the application of dispersion is one of the considering factors. Also, found that f-MWCNTs has a better result than p-MWCNTs. In each case of an ultrasonic duration of 30-90 mins, it shows functionalized MWCNTs combined with PVPk-30 \& SDS simultaneously provided a better absorbance value than others. From the above phenomenon, it can be suggested that efficiency of CNTs dispersion: PVP k-30>PVPk-90, f-MWCNTs $>p$ MWCNTs, PVPk-30+ SDS >PVP k-90+SDS as depicted in Fig. 3. The role of SDS seems to be confined to acting as an inter-phase between the hydrophobic CNTs wall and the aqueous environment [22].

For the next set of an experiment which was conducted taking two different types of CNTs (pMWCNTs and f-MWCNTs) with 0.04 wt.\% loading, CNTs/Surfactant ratio 1:05 and followed by ultrasonic treatment (50\% magnitude, $450 \mathrm{w}$ ) of an aqueous solution. The UV-Vis spectroscopy study noting absorbance values of the sample at a different wavelength the analyzed result showed that the f-MWCNTs with combination of PVPk30 has efficient result of dispersion till 120 min and was followed by low absorbance value at $150 \mathrm{~min}$. Overall the absorbance value for $180 \mathrm{~min}$ (which is optimal ultrasonic duration) which was found to be higher than other as an amazing scenario.

The recording of electrical resistance and capacitance (at $30 \mathrm{~Hz}$ frequency) of each sample with various ultrasonic time showed a sharp enhancement on electrical conductivity and capacitance of aqueous solution from 0 to $60 \mathrm{~min}$ and a slow decrease of electrical resistance and very slow increase of capacitance with prolonged ultrasonic time which is depicted in Fig. 4. Data from nonsonicated specimens are also included and compared. From the graph plotted it can be seen that higher the sonication time the higher the intensity and absorbance value. Many literature findings indicate that individual MWCNTs exhibit their characteristics peak around 260 $\mathrm{nm}$. The absorbance at specific wavelength can be related to the degree of de-bundling of the suspensions $[\mathbf{2 0 , 2 3}]$. 
(a)

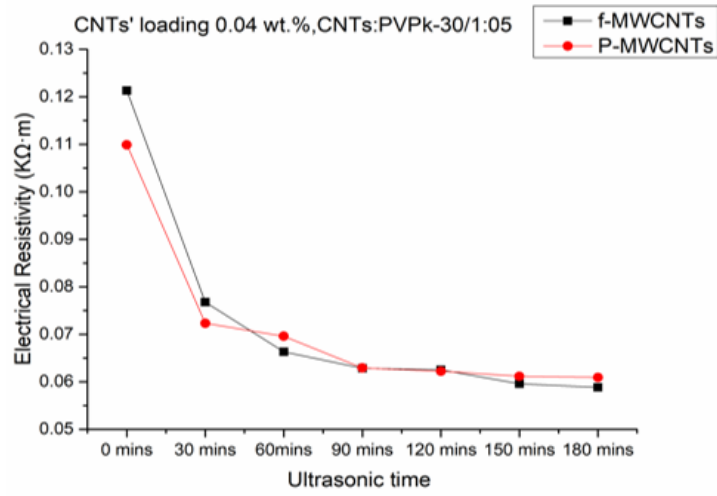

(b)

(c)
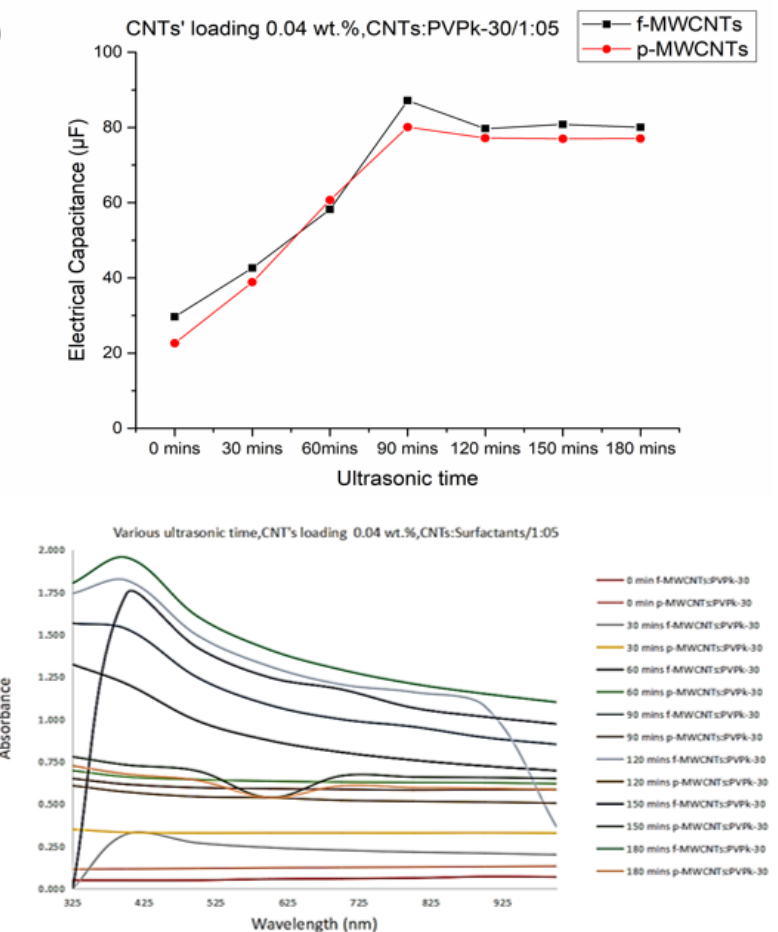

Fig. 4. Graph plotted for CNTs' loading 0.04 wt.\%, CNTs:PVPk-30/1:05 (a) Relation between ultrasonic time and electrical resistivity for $\mathrm{p}$ MWCNTs and f-MWCNTs, (b) Relation between ultrasonic time and capacitance for p-MWCNTs and f-MWCNTs measured at $30 \mathrm{hz}$ frequency, (c) Relation between absorbance vs wavelength plotted of pMWCNTs and f-MWCNTs with different ultrasonic time.

So can be predicted that sonication process brings deagglomeration and fragmentation of individual CNTs [24]. But $\mathrm{Uv}-\mathrm{V}$ is data is unable to assess mean agglomerate size so is not possible to be sure from particular data alone that provided sonication energy is optimal for deagglomeration [25].

From the next experimental study of different CNTs/Surfactant (CNTs' loading 0.2 wt.\%) ratio for p-MWCNTs \& PVP k-30 for different ultrasonic time (magnitude $50 \%, 450 \mathrm{~W}$ ) it was found that the ratio of 1:05 is the efficient ratio of dispersion as well as an economical. Since, the other higher than that ratio showed a very slow enhancement in electrical conductivity. The recorded electrical resistance (at $30 \mathrm{~Hz}$ frequency) of aqueous suspension from 0 min to $120 \mathrm{~min}$ time duration depicts the result as shown in Fig. 5 .
p-MWCNTs with 0.25 wt.\% composition was examined with PVPk-30, SDS independently as well as with both surfactant combinedly. After the aqueous suspension was prepared as above-mentioned procedure, it was performed ultrasonic treatment (50\% magnitude, 450 W) for $0 \mathrm{~min}, 15 \mathrm{~min}, 30 \mathrm{~min}, 45 \mathrm{~min}$ and $120 \mathrm{~min}$ the electrical resistance (at $30 \mathrm{~Hz}$ frequency) of aqueous solution sample was recorded then plotted the graph as shown in Fig. 5. Different \% composition (0.015 to 1.0 wt. \%) of p-MWCNTs was loaded in the $100 \mathrm{ml}$ de-ionized water with no addition of any surfactant. The electrical resistance vs different CNT's loading was plotted as shown in Fig. 5. This clearly shows that in \% composition of CNTs from 0.015 to $0.1 \mathrm{wt} . \%$ the electrical resistance decreases to lowest at $90 \mathrm{~min}$ of ultrasonic treatment whereas other CNT's loading from 0.15 to $1.0 \mathrm{wt} \%$ the optimal ultrasonic duration gave the highest enhancement of electrical conductivity. Hence, it is assumed that the ultrasonication duration is a variable factor as the $\%$ of CNTs' loading ascends in the system.

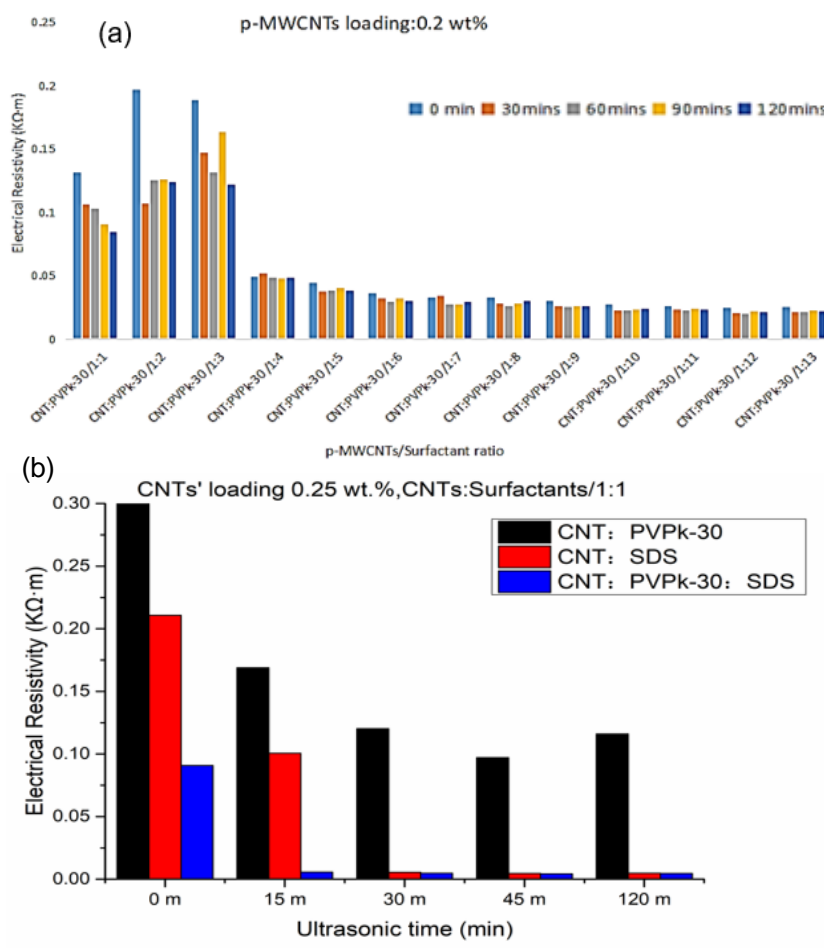

(c) With no surfactants, different CNTs loading vs ultrasonic time

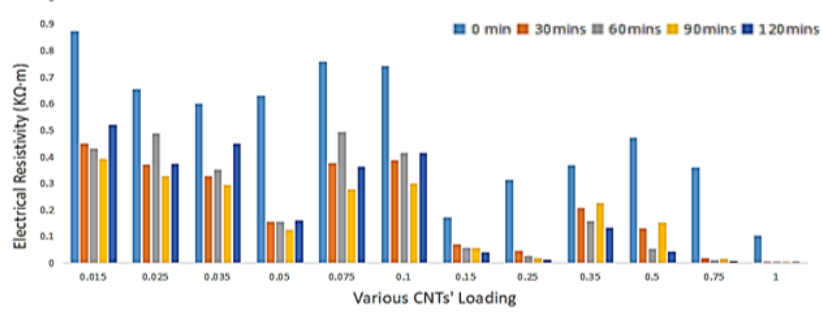

Fig. 5. (a) Relationship between electrical resistivity and varying p-MWCNTs/Surfactants ratio, (b) Graph showing enhancement of electrical conductivity of aqueous solution with combined application of PVP k-30 and SDS, (c) Graph depicting electrical resistivity of various CNTs' loading for different ultrasonic time. 


\section{Advanced Materials Letters www. vbripress.com/aml}

The above-mentioned dispersion methodology was adopted and with the integrated method of dispersion using surfactant and ultrasonication (50\% magnitude, 450 $\mathrm{W}, 120 \mathrm{~min}$ ). The surfactant used was PVPk-30 with CNTs/Surfactant ratio of $1: 5$ and cement paste was prepared. In total there were 4 sets of specimens (each 3 pieces) whose mixing proportion is illustrated in Table 3 . To study the changes in conductivity of test specimens, each test blocks were conducted for the electrical resistance measurement using Precision LCR meter and electrical resistance on $3^{\text {rd }}, 7^{\text {th }}, 14^{\text {th }}, 21^{\text {st }}$ and $28^{\text {th }}$ days were recorded and plotted in graph as shown in Fig. 6. To minimize the experiment error, the electrical resistance of each specimen was then converted to average. Electrical resistance of least \% composition $(0.001$ wt. \%) specimen was also studied on varying frequencies. It was seen that the specimen with least \% composition of CNTs found highest electrical resistance on $3^{\text {rd }}$ and $21^{\text {st }}$ curing days showing unexpected patterns. It is predicted being lower than the threshold CNTs' loading and because of which creation of voids, development of agglomeration inside the structure etc. which affected on electrical conductivity [26].
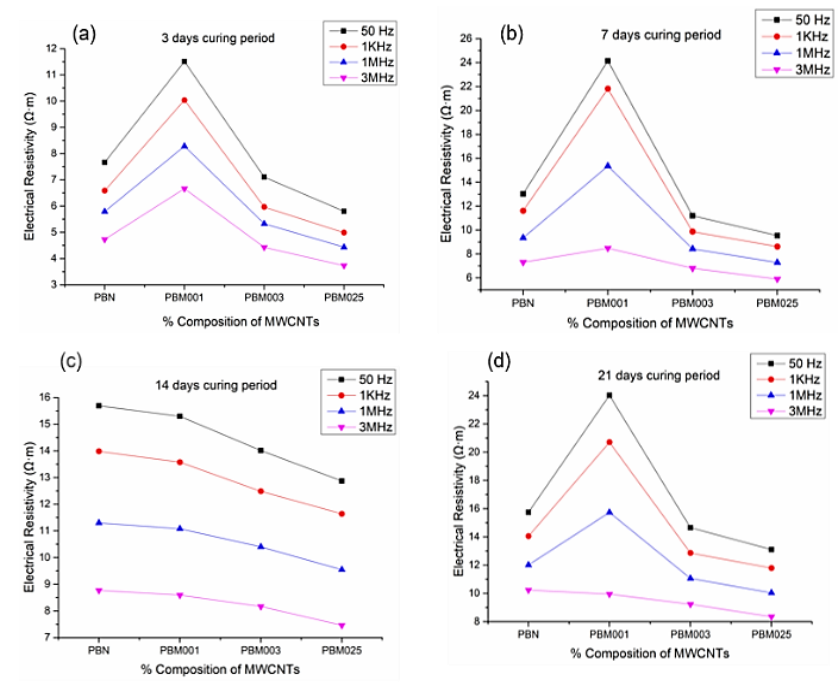

(e)

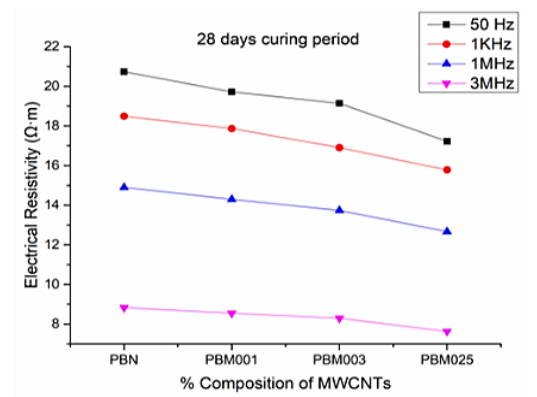

Fig. 6. Relationship between electrical resistivity and curing period for different CNTs' loaded specimen at varying frequencies.

\section{Conclusion}

Many of the popular technical approach used for the dispersion of CNTs for the application of cement-based composites has merits as well as demerits so an integrated method of dispersion is found less time consuming and economical providing good and stable dispersion enhancing the electrical conductivity of composites.

The experiment performed for the dispersion of MWCNTs in aqueous solution containing same wt.\% concentration of CNTs with variable time $0-300 \mathrm{~min}$ of ultrasonic energy implication revealed that 120 mins of ultrasonication enhanced the thermal conductivity of sample with decrement of $399.08 \%$ electrical resistivity. Also found that prolonged ultrasonication has negative effect in dispersion of CNTs. When experiment is performed taking $1.0 \mathrm{wt} . \%$ concentration of MWCNTs with PVPk-30 it is found electrical resistivity of aqueous sample decreases with increasing the concentration of CNTs. 1g of MWCNTs added with different concentration of PVP $(0.03,0.05,0.07,0.1,0.12,0.18$ and $0.2 \mathrm{~g})$ the aqueous solution is prepared and applied ultrasonication for 30min and left still for 2 hours, the measured electrical resistivity of sample decreases from $3.45744 \mathrm{~K} \Omega . \mathrm{m}$ (MWCNT1/PVP0.03) to $0.6336 \mathrm{~K} \Omega . \mathrm{m}$ (MWCNT1/ PVP0.2). This result supported integrated method of dispersion with treatment of CNTs using PVP along with ultrasonication where found PVP being a good dispersing agent for CNTs in application in cement-based composites.

The Efficiency of CNTs dispersion is found as PVP k30>PVPk-90, f-MWCNTs $>$ p-MWCNTs, PVPk30+SDS >PVP k-90+SDS. A system of CNTs + PVPk$30+$ SDS proposes a synergistic enhancement on electrical properties. The role of SDS seems to be confined to acting as an inter-phase between the hydrophobic CNTs' wall and the aqueous environment. Carbon nanotubes can modify many properties of cement composites in the fresh and hardened state but only when an appropriate dispersion of nanotubes particles is achieved. If incorporated CNTs found not being effectively dispersed in cement-based composites then circumstance wouldn't only be the negative role of particles but also the effect could be on hydration process [27], development of latestage strength, stress concentration around the sites of agglomeration of CNTs particles. Appropriate percentage composition of CNTs in a composite is another urgency for the enhancement of properties of the matrix.

The UV-Vis spectroscopy study showed that the efficiency of PVPk-90 is less than PVP k-30 for good dispersion of MWCNTs. Hence, predicted that molecular weight of applied surfactant for the application of dispersion is one of the considering factors.

The combination of PVP k-30 along with SDS found extraordinary with a combination of CNTs for enhancement of electrical conductivity of an aqueous solution. Electrical conductivity sharply increases with the beginning of ultrasonic treatment while slow increases are seen after $15 \mathrm{~min}$.

Functionalized MWCNTs (MWCNTs-COOH) was found comparatively better enhancing the dispersion efficiency comparative to pristine MWCNTs when UV-vis spectroscopy analysis is performed with all different surfactants and variable ultrasonic time duration. 


\section{Advanced Materials Letters www. vbripress.com/aml}

Visual observation, UV-Vis spectroscopy analysis of sonicated aqueous suspensions and electrical conductivity measurement of sample solution showed that CNTs: PVP $\mathrm{k}-30 / 1: 5$ ratio is enough for achieving dispersion of MWCNTs and the ratio above that could be hindering the properties of samples showing unexpected pattern and also not economical.

Following are some remarks for future works:

- More parameters of ultrasonication like duration, amplitudes, on/off pulses, probe tip diameter, frequency etc. seen necessary to consider.

- It is necessary to pay attention to the role of temperature during the ultrasonic treatment.

- Change of PH, size, concentration of particles is also another research area for further work in future.

- Careful consideration should be taken to evaluate whether the improvement in dispersion does enhance the desired functionality in composite.

\section{Acknowledgements}

This Research is supported by Project of Natural Science Foundation of Fujian Province (Grant No. 2019J01060795), by Project of IndustryUniversity Cooperation and Education (GaoJiao Si Inform [2019]12), by Project of Department of Education of Fujian Province (No.20181039701), by Young Doctoral Discipline Team of Wuyi University (Wuzong $(2017,66)$, and by Project of Innovation Experiment Project (Grant No.201810397015 and No.201910397073). The authors gratefully acknowledge the support from Wuyi University Department of Civil Engineering and Architecture and Overseas Education College.

\section{Author's contributions}

Conceived the plan: Ghimire Prateek, Yulin Wang; Performed the experiments: Henggan Li, Yuanfu Ban, Hao Luo, Danping Lin; Data analysis: Jinglong Yang, Zhengyang Pan, Shuyan Lin, QingWei Su; Wrote the paper: Ghimire Prateek. Authors have no competing financial interests.

\section{Keywords}

Carbon nanotubes, cement-based materials, dispersion, integrated dispersion method, polyvinylpyrrolidone, surfactant.

Received: 22 July 2019,

Revised: 13 December 2019

Accepted: 23 December 2019

\section{References}

1. Monthioux, M.; Kuznetsov, V.L.; Carbon; 2006, 44, 1621.

2. Iijima, S.; Nature; 1991, 354, 56.

3. Kroto, H.W.; Heath, J.R.; O'Brien, S.C.; Curl, R.F.; Smalley, R.E.; Nature; 1985, 318, 162.

4. Eguilaz, M.; Dalmasso, P.R.; Rubianes, M.a.D.; Gutierrez, F.; Rodriguez, M.C.; Gallay, P.A.; L | pez Mujica, M.E.J.; Ramirez, M.a.L.; Tettamanti, C.S.; Montemerlo, A.E.; Rivas, G.A.; Current Opinion in Electrochemistry; 2019, 14, 157.

5. Vilela Rocha, V.; Ludvig, P.T.; Const Fóncio Trindade, A.C.; Andrade Silva, F.í. de; Construction and Building Materials; 2019, 209,1

6. Hunashyal, A.; Advances in Materials; 2014, 3.

7. Mohsen, M.O.; Taha, R.; Abu Taqa, A.; Shaat, A.; Construction and Building Materials; 2017, 150, 395.

8. Wilder, J.W.G.; Venema, L.C.; Rinzler, A.G.; Smalley, R.E.; Dekker, C.; Nature; 1998, 391, 59.

9. Terrones, M.; Terrones, H.; Dresselhaus, M.S.; Dresselhaus, G.; Charlier, J.C.; Hern Fíndez, E.; Philosophical Transactions of the Royal Society of London. Series A: Mathematical, Physical and Engineering Sciences; 2004, 362, 2065.
10. Lim, Y.D.; Kong, Q.; Wang, S.; Tan, C.W.; Tay, B.K.; Aditya, S.; Applied Surface Science; 2019, 477, 211

11. Wu, X.; Wang, C.; Wang, Y.; Zhu, Y.; International Journal of Heat and Mass Transfer; 2019, 140, 671.

12. Gan, L.; Shang, S.; Mei, C.; Xu, L.; Tan, L.; Hu, E.; Chapter Three - Wet Functionalization of Carbon Nanotubes and Its Applications in Rubber Composites, in: S. Yaragalla, R. Mishra, S. Thomas, N. Kalarikkal, H.J. Maria (Eds.), Carbon-Based Nanofillers and Their Rubber Nanocomposites, Elsevier, 2019, pp. 77-108.

13. Vedrtnam, A.; Gunwant, D.; Materials Research Express; 2019, 6, 105408 .

14. Vedrtnam, A.; Composites Part B: Engineering; 2019, 157, 305.

15. Vedrtnam, A.; Gunwant, D.; Composites Part B: Engineering; 2019, 175, 107089 .

16. Vedrtnam, A.; Sharma, S.P.; Composites Part A: Applied Science and Manufacturing; 2019, 125, 105509.

17. Bastos, G.; Patino-Barbeito, F.; Patino-Cambeiro, F.; J. Armesto, Materials (Basel); 2016, 9.

18. Inam, F.; Heaton, A.; Brown, P.; Peijs, T.; Reece, M.J.; Ceramics International; 2014, 40, 511

19. Awasthi, R.; Manchanda, S.; Das, P.; Velu, V.; Malipeddi, H.; Pabreja, K.; Pinto, T.D.J.A.; Gupta, G.; Dua, K.; Poly (vinylpyrrolidone), Engineering of Biomaterials for Drug Delivery Systems, 2018, pp. 255-272.

20. Rausch, J.; Zhuang, R. C.; M Fñder, E.; Surfactant assisted dispersion of functionalized multi-walled carbon nanotubes in aqueous media, 2010, pp. 1038-1046.

21. Namasivayam, M.; Andersson, M.R.; Shapter, J.; Polymers (Basel); 2019, 11 .

22. Bricha, M.; El Mabrouk, K.; Colloids and Surfaces A Physicochemical and Engineering Aspects; 2019, 561, 57.

23. Jiang, L.; Gao, L.; Sun, J.; Journal of Colloid and Interface Science; 2003, $260,89$.

24. Chen, S.J.; Qiu, C.Y.; Korayem, A.H.; Barati, M.R.; Duan, W.H.; Powder Technology; 2016, 301, 412.

25. Alafogianni, P.; Dassios, K.; Farmaki, S.; Antiohos, S.K.; Matikas, T.E.; Barkoula, N.M.; Colloids and Surfaces A: Physicochemical and Engineering Aspects; 2016, 495, 118.

26. Dong, W.; Li, W.; Tao, Z.; Wang, K.; Construction and Building Materials; 2019, 203, 146

27. Balasubramaniam, B.; Mondal, K.; Ramasamy, K.; Palani, G.S.; Iyer, N.R.; Fibers; 2017, 5. 